\title{
AUTOMAÇÃO DO PROCESSO DE VENDAS NO CONTEXTO DO GERENCIAMENTO DE CLIENTES POR CRM
}

\author{
SALES PROCESS AUTOMATION IN THE \\ CLIENT'S MANAGEMENT CONTEXT \\ TROUGH CRM
}

Recebido 29/07/2010

Aceito $10 / 12 / 2011$

Flávio Régio Brambilla ${ }^{1}$

\section{RESUMO}

Na gestão dos relacionamentos com clientes, ou Customer Relationship Management (CRM), a Sales Force Automation (SFA), ou Automatização da Força de Vendas, exerce um impacto significativo tanto tecnológico quanto relacional. Mediante um Estudo de Caso na relação entre uma empresa desenvolvedora e outra usuária de CRM, resultados indicam que, ao contrário da teoria, a aplicação de automação nem sempre é percebida pelo pessoal de vendas como uma ameaça, mas como uma ferramenta de apoio. Supõe-se que a prontidão tecnológica das organizações exerça impacto para que os resultados obtidos estejam contrários aos pressupostos teóricos gerais.

Palavras-chave: Gestão do relacionamento com o cliente; Automação da força de vendas; Marketing de relacionamento; Tecnologia; Negócio.

\footnotetext{
${ }^{1}$ Doutor em Administração (UNISINOS). Mestre em Administração e Negócios: Marketing (PUC/RS). Professor do Centro Universitário La Salle (UNILASALLE), Canoas, Rio Grande do Sul, Brasil. Email: flaviobrambilla@terra.com.br
} 


\section{ABSTRACT}

TIn the management of customers' relationships or Customer Relationship Management (CRM), the Sales Force Automation (SFA), or automation of the sellers, evoke a significant impact in technological as in relational side. Trough a Case Study in the relationship between a developer company and other company as user of CRM, results indicate that, contrary to the theory, the automation not always is noticed by the personnel of sales as a threat, but as a supporting tool. It is supposed that the technological readiness of the organizations exercises impact to obtaining contrary results in front of the general theoretical propositions.

Keywords: Customer relationship management (CRM); Sales force automation (SFA); Relationship marketing; Technology; Business.

\section{INTRODUÇÃO}

Para avançar em termos de Sales Force Automation (SFA), primeiramente se faz preciso contextualizar o ambiente no qual este indicador tecnológico do CRM está inserido. Nesse sentido, dois conceitos são essenciais. O primeiro é o de Marketing de Relacionamento, no qual a interação com os clientes passa a ser o foco nas transações. O segundo conceito é uma extensão do primeiro, o Customer Relationship Management (CRM). As dimensões operacionais do CRM são duas, tecnológica e organizacional. Este trabalho centraliza na dimensão tecnológica, referindo-se em particular à variável SFA e seus indicadores propostos. Tendo em vista a cadeia de conceitos relacionados, o começo da discussão concentra o foco na base filosófica do CRM, que são as perspectivas e virtudes do relacionamento com cliente.

O Marketing de Relacionamento não é uma atenção mercadológica nova direcionada aos clientes e envolve as transações entre empresas e clientes ao longo do tempo. Max Weber em A Ética Protestante e o Espírito do Capitalismo já apresentara uma idealização muito similar aos padrões genéricos do CRM, exceto pela aplicação tecnológica que vem ganhando força nas últimas décadas. Para Weber (2003, p.60), "de mais a mais, além da clareza de visão e da habilidade para agir, somente pela virtude de qualidades éticas bem definidas e altamente desenvolvidas é possível merecer a confiança, absolutamente indispensável, dos clientes". Para o entendimento do CRM, é preciso conhecer a lógica que suporta sua operacionalização, que é o Marketing de Relacionamento. Somente organizações com um forte e positivo relacionamento com os clientes, dizem Rowe e Barnes (1998), têm potencial para desenvolver uma vantagem competitiva sustentável que pode conduzir ao desempenho superior. A premissa fundamental do Marketing de Relacionamento consiste em manter uma base de clientes rentáveis e fiéis. Estes são os pilares de resultados da organização, o que Berry (2002, p.70) apresenta como o elemento "para que os clientes continuem sendo clientes".

Como uma extensão do tradicional marketing referente aos relacionamentos, a aplicação ampliada e suportada por tecnologia constitui Customer Relationship Management (CRM), o gerenciamento dos relacionamentos com os clientes. É uma abordagem gerencial propiciada às organizações na identificação, na atração e no aumento da retenção dos clientes. Uma das diferenciações desse segundo conceito é o suporte tecnológico, embora não seja a essência da aplicação. O CRM proporciona rentabilidade para a empresa desenvolvendo ações para a identificação e para o aumento das transações com os clientes de maior valor para a firma (WILSON, DANIEL, McDONALD, 2002). Lin e Su (2003, p.716) definem CRM como "a chave da competição estratégica necessária para manter o foco nas necessidades dos clientes". Uma abordagem técnica, apresentada por Wilson, Daniel e McDonald (2002), traz o CRM como conjunto de processos e tecnologias que

Rev. Adm. UFSM, Santa Maria, v. 5, n. 1, p. 29-46, jan./abr. 2012 
suportam planejamento, execução e monitoramento coordenados dos consumidores. Para Dwyer, Schurr e Oh (1987), a extensão dos relacionamentos de troca contribui para a diferenciação de

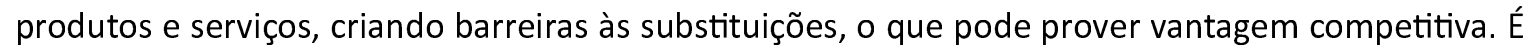
relatado por Berry (2002) que bons serviços são necessários para que a retenção dos relacionamentos ocorra. Diz Winer (2001) ser a meta global dos programas de relacionamento entregar alto nível de satisfação ao cliente, superando o entregue pela concorrência. O estudo de Ernst et al. (2011) destaca os aspectos da coleta, análise e transformação dos dados em informações a serem utilizadas nos negócios, como ponto estratégico na gestão dos relacionamentos com clientes. Os autores expandem a análise das práticas tradicionais de CRM para produtos consolidados ao CRM como estratégia de interação perante novos produtos e serviços.

Uma abordagem importante do CRM como estratégia de marketing pode ser observada através das métricas de clientes propostas por Croteau e Li (2003). Estes três indicadores estão abaixo apresentados e contextualizados.

1) Taxa de retenção de clientes: refere-se à retenção dos clientes existentes, também considerando a segmentação entre novos, antigos e repetidos e, em especial, clientes leais. Consiste na verificação de um nível interno de satisfação que é relativo às aplicações de CRM implantadas. Também diz respeito às mudanças na estratégia de negócios da organização, estrutura, processo de negócio, compensações, habilidades e tecnologia.

2) Satisfação do cliente: trata-se do grau de satisfação do cliente devido à introdução de produtos e serviços inovadores, de melhores tempos de entrega e que estas se deem em tempo adequado. Diz respeito à antecipação das necessidades, à customização, à conveniência e ao espírito de equipe. É de foco externo, englobando o nível de satisfação dos clientes devido à implantação das aplicações de CRM. O foco externo lida com a definição e segmentação dos clientes, suas necessidades, suas expectativas, seu feedback e suas comunicações em geral.

3) Lucratividade do cliente: é referente à posição da organização em relação aos concorrentes, em termos dos custos de clientes por segmento de mercado. Incorpora segmentação de mercado e carteira de clientes em segmentos alvo.

Segundo Croteau e Li (2003), existem fatores diferenciadores nas práticas e nos sistemas de CRM. Os resultados demonstram, por exemplo, que o suporte da alta administração constitui um dos elementos críticos do sucesso em relacionamento com o cliente. Esses preceitos são fundamentais quando iniciativas de CRM são adotadas, sendo o suporte da alta administração, ou alta gerência, apresentado como crucial para a implementação, com sucesso, de um programa de CRM. Entende-se que, se os executivos não demonstram algum interesse ou envolvimento no processo, os membros da organização não acreditarão em tais projetos e terão a tendência de resistência em vez de decidirem por adesão ao projeto.

Outro aspecto abordado e comprovado em Croteau e Li (2003) indica que a posse de capacidades de administração do conhecimento consiste no mais significante fator crítico do sucesso, exercendo impacto ao CRM. Resultado que sugere um elevado nível de capacidades de administrar o conhecimento e que nutre um adequado gerenciamento do relacionamento com o cliente. É possível afirmar que a posse de uma sólida infraestrutura de tecnologia da informação é pré-requisito importante ao desenvolvimento da capacidade de administração do conhecimento, mas não é um critério isolado.

A infraestrutura de tecnologia da informação serve para capturar, gerenciar e entregar em tempo real, ao cliente, informações sobre produtos e serviços para melhorar a resposta dos consumidores e prover rápida tomada de decisão em todos os pontos junto ao cliente. As estratégias de negócios por CRM são apropriadas para identificar os líderes de mercado, mas riscos e recompensas são igualmente altos (CROTEAU, LI, 2003). Dando-se continuidade na conexão dos assuntos, segue a apresentação geral do que é o emprego de tecnologia em CRM. 


\section{INICIATIVAS TECNOLÓGICAS EM CRM}

As iniciativas tecnológicas de CRM obtêm o sucesso quando conseguem adequar o suporte da administração de cúpula e a capacidade de administrar conhecimento, suportados por adequada infraestrutura de Tecnologia da Informação (TI), medida por prontidão tecnológica. Para Lin e Su (2003), CRM pode habilitar negócios a um melhor entendimento do que é declarado, especialmente com relação às implicações e exigências dos consumidores.

OCRM pode, ainda, contribuir para a excelência nos negócios, possibilitando uma capacidade de manter sintonia com as exigências dos consumidores e aumentando os relacionamentos com estes e sua satisfação. Conforme Im e Workman Jr. (2004, p.114), é "a orientação de marketing direciona para um melhor desempenho na organização".

Ocorrência recente é que as organizações despertaram para a realidade de que seus clientes constituem os melhores ativos. Nesse sentido, Croteau e Li (2003) destacam que um grande número de organizações reconhece a importância de focar seus negócios em uma estratégia de orientação ao cliente que inclua uma base de conhecimento referente aos mesmos. Esta pode ser definida como uma coleção organizada de informações para CRM. O'Malley e Mitussis (2002) alertam que, na ausência de uma cultura centrada em Marketing de Relacionamento, não serão entendidos os processos envolvidos no desenvolvimento das ações de CRM. A ausência da compreensão de processos preconiza e reforça a ideia de que o CRM não se trata de uma solução de cunho tecnológico, mas sim tecnológico e relacional.

Além da atenção voltada ao mercado e aos aspectos de valor considerados pelos clientes, as organizações devem estar adequadas quanto ao suporte tecnológico utilizado. Para o adequado funcionamento da filosofia adotada pela empresa, torna-se imprescindível que o aparato tecnológico utilizado no processo seja funcional e adequado. Um programa de CRM, para ser estrategicamente efetivo, segundo Ragins e Greco (2003), requer uma inteligente aplicação de tecnologia. Entretanto, conforme já mencionado anteriormente, o CRM é mais do que uma solução de software, haja vista que se refere à maneira como as informações dos consumidores são utilizadas para criar uma relação contínua com os mesmos.

Kavanagh $(2003$, p.39) destaca que o "CRM demanda que as organizações adotem uma filosofia de negócio centralizada no cliente. Assim, recursos humanos e processos de negócio são capazes de fazer um melhor uso das tecnologias de CRM". As TIs oferecem ao pessoal de marketing a oportunidade de embutir noções através das informações dos clientes em relação às melhores práticas de vendas, à logística e ao serviço ao cliente, existentes no âmbito de uma organização (WILSON, DANIEL, MCDONALD, 2002).

Lin e Su (2003, p.726) dizem que "o sistema de CRM pode ser efetivamente utilizado para acumular o conhecimento de clientes com o objetivo de prover melhores serviços". A utilização do conhecimento de clientes integrada com o sistema de CRM pode ser enfatizada para manter e criar novos parceiros na cadeia de valor agregado como um todo. Winer (2001) diz que o primeiro e necessário passo para uma solução completa de CRM requer a construção de uma base de dados de clientes ou de arquivos de informação completos e corretos.

A importância da elaboração de um sistema de CRM com a capacidade de ser modificado para o atendimento das necessidades futuras da empresa é hoje uma implicação reconhecida e aceita. Clientes não são ativos estáticos, variando no decorrer do tempo.

Conforme Wilson, Daniel e McDonald (2002), programar um CRM integrado ou adicionar um canal de internet, por exemplo, consiste em uma grande transição de trabalho. AtuaheneGima e Murray (2004, p.37) dizem que "mudanças tecnológicas tendem a progredir por trajetórias definidas, através das quais as empresas podem reconhecer e entender as direções de mudança", 
fator que demonstra a necessidade e importância da elaboração do planejamento das ações e das ferramentas de CRM adotadas pela empresa. 0 elemento humano é diretamente afetado nas mudanças. Ragins e Greco (2003, p.25) relatam que "uma estratégia efetiva de e-business requer que a organização proporcione valor aos clientes, os quais devem ser superiores aqueles oferecidos pelos concorrentes", superando a utilização de um aplicativo como fim, mas utilizando-se deste como um meio transacional. O CRM on-line é considerado como uma maneira de aumentar o valor de relacionamento para ambos: clientes e comércio, por meio eletrônico. Nessa relação, os clientes podem receber mais produtos e comunicações, as quais são mais bem direcionadas para suas necessidades e seus estilos de vida. $\mathrm{O}$ e-business pode beneficiar clientes de alto valor, que podem se tornar clientes de repetição. Novamente, o pessoal de vendas é crucial embora, por vezes, esquecido em teorias de TI.

Implementação do CRM, dizem O'Malley e Mitussis (2002), em muitas organizações, requer a confiança nas soluções de TI devido a uma extensiva, ou, por vezes, imensurável quantidade de dados envolvida. Algumas das novas tecnologias propiciam a abertura de novos canais de diálogo, que podem iniciar pelos clientes, bem como podem ser iniciados pelas organizações. A base de dados tornou-se ferramenta essencial de conhecimento para as organizações dentro de uma estratégia no Marketing de Relacionamento. Para Rogers (2003), desenvolver software requer que este seja submetido a um rigoroso gerenciamento de projeto, incluindo completo conhecimento e entendimento dos pré-requisitos, correquisitos, marcos, padrões críticos, riscos envolvidos e contingências. A disponibilidade de amplos volumes de dados dos clientes é possível através das novas ferramentas tecnológicas disponíveis. Isso remete à criação de oportunidades e de desafios para os negócios, através da utilização desses conjuntos de dados, podendo resultar em ganhos de vantagem competitiva (LIN, SU, 2003).

Iniciativas tecnológicas de CRM, conforme Croteau e Li (2003), baseiam-se em sistemas de suporte à decisão e em fontes de informações integradas que aumentam o valor dos recursos dos clientes, provendo uma visão individual de cada cliente e suas respectivas necessidades particulares. A conversão de informações em conhecimentos pode ser utilizada como forma de criar planos de marketing personalizados, que podem atingir os targets em cada segmento de clientes definido. Entretanto, Croteau e Li (2003) chamam a atenção para o fato de que a prontidão tecnológica não é o fator direto resultante ao impacto positivo do CRM. As iniciativas tecnológicas de CRM são muito maiores do que as inovações tecnológicas e não são apenas dirigidas por intermédio da tecnologia, mas por preceitos mercadológicos, geralmente atrelados aos pensamentos estratégicos da área de marketing e da força de vendas.

\subsection{Dificuldades enfrentadas em iniciativas tecnológicas de CRM}

É citado, por Olsen (2002), que métricas constituem um problema central nas pesquisas de avaliação dos fatores qualidade e satisfação, o que não difere quando se fala em CRM. Para Rogers (2003), na realidade, as medições recebem baixos investimentos. Rogers (2003, p.25) referencia que "as implementações de CRM vem sendo medidas de maneira muito pobre". Contudo, verificase, em muitas organizações, a consciência da necessidade do desenvolvimento de medidas mais sofisticadas (NANCARROW, REES, STONE, 2003).

Winer (2001) diz que os gerentes devem constantemente medir os níveis de satisfação e desenvolver programas que ajudem a entregar, mediante melhor desempenho, as expectativas dos clientes. De certo modo, isso significa que as métricas tradicionais, usadas pelos gerentes para medir o sucesso de seus produtos e serviços nos mercados, necessitam de atualização para essa diferente realidade. No CRM, existe uma ênfase crescente no desenvolvimento de métricas 
centralizadas nos clientes, as quais propiciam aos gerentes uma melhor ideia de como suas políticas de CRM e seus programas estão trabalhando na prática. Conforme Nancarrow, Rees e Stone (2003), variáveis e medidas de retenção diferem em relevância e em importância de categoria para categoria em produtos e serviços. Identificar a melhor definição e as melhores medidas é essencial para que a organização avalie o desempenho e estabeleça a relação de seu resultado com as ações no mercado. Quanto maior a organização e sua base de dados, mais são desejadas que ações sejam medidas. Existe muito a ser feito, em termos organizacionais, para que se obtenham claras definições e medidas operacionais apropriadas. Conhecimento do cliente, tecnologias de conexão com o cliente e economias de cliente são as fundações de uma estratégia conectada de clientes (LIN, SU, 2003). Além da complexidade das medições, existem outras dificuldades a serem consideradas em se tratando dos programas de CRM.

Primeiramente, é importante que seja feita a distinção existente na relação entre CRM e tecnologia, a qual, conforme apresentado por Ragins e Greco (2003, p.29), reside no fato de que o "CRM é uma estratégia de negócio; não apenas um aparato de software". Outro ponto crucial a ser verificado em termos de CRM é apontado por Croteau, Li (2003) quando afirmam que os projetos de CRM podem alcançar alguns dos mais altos Retornos sobre Investimento (ROI), mas também respondem por uma das mais altas taxas de falhas e risco.

O problema, de acordo com Winer (2001), é que CRM tem significados diferentes para diferentes pessoas. Para alguns, o CRM significa envio de e-mails diretos, para outros consiste em customização de massa ou desenvolvimento de produtos, os quais são ajustáveis de acordo com as necessidades individuais. Já para consultores da área de TI, um CRM traduz-se em complicados jargões referentes a tecnologias relacionadas com alguns termos como, por exemplo, On-Line Analytical Processing (OLAP), e Customer Interaction Centers (CICs). Aproximações através do marketing de massa, como televisão, rádio ou anúncios impressos, são utilizadas para a criação de uma espécie de consciência geradora, alcançando, assim, outros objetivos de comunicação. Porém, estes são considerados inadequados ao CRM devido à natureza impessoal de utilização. Winer (2001) destaca que aproximações mais convencionais para atingir os selecionados como clientes potenciais incluem um agregado de métodos de marketing direto. Como exemplo, TeleMarketing, mala direta, e, quando a natureza do produto é satisfatória, vendas diretas. No estudo de Winer (2001), foram identificados três problemas comumente ocorridos nos programas destinados ao CRM, sendo esses:

1) custo elevado;

2) enganos de difícil correção referentes à maneira como os clientes veem a empresa, no sentido do abandono de benefícios;

3) amplas questões de discussão sobre o CRM como uma forma de geração de lealdade ou como um comportamento de gastos.

Informações sobre clientes são críticas. Como dito por O'Malley e Mitussis (2002), para o desenvolvimento e a manutenção dos relacionamentos com os clientes, a presença das informações destes em tempo hábil é fundamental ao sucesso das transações. Outro ponto importante é referido por Schiffman e Kanuk (1997, p.89), quando salientam que, em termos de produtos e serviços, "muitas das necessidades humanas não são completamente ou permanentemente satisfeitas". Estas devem ser observadas quando se trata da utilização de um sistema de CRM. As soluções para os problemas e lacunas, existentes nos sistemas e nas metodologias de trabalho permeado pelo conceito e pelas ferramentas de CRM, competem aos gestores do futuro, bem como as progressivas iniciativas e melhorias tomadas pelos gestores da atualidade. É pertinente abordar as perspectivas futuras do CRM, o que não significa esquecer que CRM, em essência, se refere a uma extensão das ações do Marketing de Relacionamento. 


\subsection{Perspectivas futuras diante das iniciativas tecnológicas de CRM}

Conforme Nancarrow, Rees e Stone (2003), pesquisas qualitativas com os clientes e discussões com os operadores organizacionais da linha de frente e os gerentes da primeira linha podem ajudar a identificar diferentes maneiras através das quais as organizações podem conquistar seus clientes. Vale citar Winer (2001), quando relata que a noção da satisfação dos consumidores vem sendo expandida para mudar de Customer Relationship Management (CRM) para Customer Experience Management (CEM). A ideia por trás desse postulado é a de que os números de pontos de contato com clientes estão em constante crescimento. É mais crítica do que nunca a realização da medição das reações dos clientes por contatos e, dessa forma, realizar o desenvolvimento de respostas imediatas para experiências negativas, o que se conhece como ações de recuperação da reputação com os clientes posterior a uma primeira má impressão de negócio. Rogers (2003) complementa o raciocínio quando afirma que métricas de CRM devem incluir a construção do senso de patrimônio líquido de clientes.

Como outro ponto crítico, é possível referenciar que o cliente pode até endossar o que a companhia fez no passado por ele, mas continua interessado preponderantemente em soluções e escolhas que Ihe proporcionarão benefícios futuros. Entretanto, Ragins e Greco (2003, p.29) lembram que o "CRM continua sendo relacionamento". Pode-se constatar que CEM tem uma abordagem geral muito similar ao CRM, focada no cliente. O CRM deve ser integrado em todas as funções de negócio, considerando que um CRM orientado por marketing pode suprir informações para a gerência do desenvolvimento de produtos, Product Development Management (PDM). O que inclui, todavia, os processos da cadeia de gerenciamento de suprimento Supply Chain Management (SCM). Proporciona-se, assim, um maior valor para a empresa e para os clientes. É preciso verificar se a modificação na denominação dessas práticas junto aos clientes de CRM para CEM faz sentido, ou se o novo conceito se trata de ampliação ou de complemento da definição e dos atributos referentes ao CRM e, na verdade, não agrega nada de novo, mas reestrutura a caracterização dos elementos constituintes do CRM.

No futuro, o CRM, junto da Gestão do Conhecimento, será mais estudado para acumular o conhecimento do cliente, construindo melhores relacionamentos, aumentando satisfação, e a excelência nos negócios. O CRM pode criar valor para o cliente, e o valor do relacionamento é reconhecido, especialmente por empresas atuantes no setor de serviços (LIN, SU, 2003). Parasuraman e Colby (2002, p.17) destacam a existência de uma disciplina do marketing conhecida como Marketing para Produtos Inovadores, que é especificamente voltada para os estudos da complexidade presente na tecnologia e em suas características particulares. Os referidos autores consideram que "o marketing para produtos inovadores é a ciência e prática de comercializar os produtos e serviços que são inovadores e de alta tecnologia". Este, por sua vez, deve ser visto como um ramo da ciência do marketing, graças aos fatores críticos de sucesso singulares quando há tecnologia envolvida. Os fatores que conduzem aos relacionamentos satisfatórios com clientes são diferentes na tecnologia (PARASURAMAN, COLBY, 2002).

Sheth, Eshghi e Krishnan (2002) referenciam que já é possível perceber as mudanças rápidas que estão ocorrendo no comportamento humano através do impacto causado pela mais recente revolução tecnológica. As mudanças no comportamento do mercado que estão ocorrendo cada vez com maior intensidade são oriundas dessa evolução. Perante essa opinião, é válido citar Weber (2003, p.60) novamente, quando ele menciona o fato de que "o interesse social e comercial dos homens tende a determinar suas opiniões e atitudes", solidificando a necessidade dos sistemas de CRM de evoluírem de acordo às necessidades das pessoas. 
É fundamental nos negócios que empresas atendam e acompanhem as premissas variáveis e voláteis emergidas do mercado, aquelas surgidas das necessidades apresentadas pelos clientes. As ações do Marketing de Relacionamento, bem como os sistemas de CRM, devem evoluir no sentido de atender as novas perspectivas e o aumento da exigência dos consumidores. Dentro dos aspectos evolutivos, a Sales Force Automation (SFA) aparece como uma importante ampliação e melhoria no desempenho dos negócios por meio da tecnologia incorporada ao CRM. É pertinente, então, apresentar a caracterização teórica do conceito de SFA perante o Estudo de Caso que foi realizado.

O estudo desenvolvido com base nos preceitos teóricos do CRM incorporou uma situação de desenvolvimento do software de CRM. Assim, a investigação se concentrou em uma desenvolvedora de soluções e em outra empresa cliente e usuária dessas soluções. Também entrevistas com especialistas da área de tecnologia de negócios foram importantes no auxílio da identificação dos fatores críticos e essenciais contemplados na pesquisa.

Como o foco da investigação é a SFA, a empresa desenvolvedora foi selecionada porque desenvolve aplicativos de CRM, dentre os quais, aqueles referentes ao melhoramento dos processos de vendas. Nesse sentido, foram verificadas as percepções no contexto entre empresas, especialmente diante destes dois pontos de vista: empresa cliente em comparação com outra firma cliente e usuária de CRM. Tem-se, a seguir, a caracterização teórica da SFA.

\section{CARACTERIZAÇÃO TEÓRICA DA SALES FORCE AUTOMATION (SFÁ)}

Na definição proposta pelo Peppers e Rogers Group (2001), a Sales Force Automation (SFA) refere-se ao software para automatização da força de vendas, que inclui: gestão de contatos, previsão de vendas, gestão de vendas e vendas em grupo. É relatado que SFA está se tornando parte integrante das soluções de CRM, justificando a abordagem dessa ferramenta neste estudo. Hansotia (2002) menciona que o principal foco do CRM em caráter operacional concentra-se na plataforma tecnológica que suporta as interações com os clientes e a automação das vendas. Relata Shoemaker (2001) que a maioria dos provedores de software de CRM tem suas raízes em SFA, a automação da força de vendas. O tamanho da funcionalidade de CRM é projetado para aumentar vendas e proporcionar melhorias na administração das vendas. As funções primárias do CRM, direcionadas para a força de vendas, são administração de contatos, localização ativa das contas, administração das contas, entrada de pedidos, geração de propostas, suporte técnico e processo de vendas.

Destacam Speier e Venkatesh (2002, p.98) que "as tecnologias de automação da força de vendas (SFA) estão sendo cada vez mais utilizadas no suporte das estratégias de CRM" e que as ferramentas de automação da força de vendas são frequentemente implementadas para facilitar os processos de CRM como parte da filosofia do Marketing de Relacionamento. Através do melhoramento na velocidade e da qualidade do fluxo de informações entre vendedores, cliente e organização, as ferramentas de SFA apoiam no processo de vendas. As ferramentas para SFA variam em complexidade e em grau para cada integração, em relação à existente infraestrutura organizacional.

No artigo desenvolvido por Speier e Venkatesh (2002), no qual se trata especialmente sobre SFA, têm-se o direcionamento e as premissas para o entendimento dessa variável, no qual se diz que é importante implementar e integrar as apropriadas ferramentas de SFA em tarefas orientadas para vendas. É requerido, da empresa adotante, o dever de assumir uma apropriada orientação tecnológica para o cliente. Esta deve ser ajustada ao processo de implantação, para que se atinjam os objetivos, melhorando a tomada de decisão e a produtividade, que serão resultados racionais da SFA. Para Speier e Venkatesh (2002), algumas características organizacionais podem ter influência significante na implementação tecnológica de sucesso, também impactando na aceitação da SFA. É fato que o 
pessoal de vendas reage de forma razoavelmente positiva para as ferramentas de SFA, imediatamente após o treinamento. Mas essa resposta inicial se torna negativa após o pessoal de vendas utilizar as ferramentas por mais tempo. A equipe de vendas deve estar envolvida na elaboração do processo e ser adequadamente treinada para manter efetividade na utilização.

Os agentes organizacionais responsáveis pela tomada de decisão devem estar ativamente envolvidos na administração e no entendimento do grau, com o qual as tecnologias de SFA irão aumentar o papel de vendas e do processo de vendas antes da compra e da implementação dessas ferramentas. Speier e Venkatesh (2002, p.110) destacam que as "empresas precisam avaliar proativamente como as ferramentas SFA mudam o papel dos vendedores e identificar as capacidades destes vendedores que são mais apropriadas" nesse contexto. Tem-se que os vendedores podem acreditar que seu papel está ameaçado, como os administradores devem ter acesso a todas as informações que eles possam ter sobre clientes, as quais aumentam o diferencial de poder entre administradores e pessoal de vendas, em favor dos gestores. As organizações devem estar atentas quanto a essas percepções, para tomar decisões tecnológicas, as quais evitem as ocorrências de divergências dessa natureza.

Finalizando-se o enfoque de Speier e Venkatesh (2002) em sua pesquisa, a demonstração empírica de que a tecnologia e, especificamente, as ferramentas SFA podem gerar excessivos conflitos internos com o pessoal de venda é apontada como uma das consequências negativas da automação de vendas. Esses conflitos resultam em custos organizacionais significantes, em eventuais perdas financeiras, mas principalmente em uma crítica perda dos empregados de valor. Se os gestores responsáveis entenderem e proativamente avaliarem o potencial desse conflito e, então, implementarem mecanismos para administrá-lo apropriadamente, empresas poderão ter uma melhor chance de obter sucesso mediante a utilização das ferramentas e práticas de SFA.

Para o Peppers e Rogers Group (2004), o termo automatização da força de vendas tem sido amplamente utilizado embora não seja exato. A utilização da tecnologia e de sistemas em si não automatiza as vendas ou os vendedores. A referida utilização pode sim automatizar algumas etapas do processo de vendas e, com isso, forçar a disciplina na adesão aos processos definidos pela empresa. Os requisitos da aplicação dessas ferramentas devem evoluir a partir do processo de vendas da empresa, não ao contrário. Quando implementado de forma adequada, o sistema de automação de vendas reduz a duração dos ciclos dos processos relacionados com o cliente, o desperdício, principalmente de tempo, e melhora a relação com o cliente, atendendo, então, os aspectos elementares do CRM.

Além do mais, a organização passa a ter uma visão melhor do cliente, tomando conta dessa relação transacional. $O$ vendedor não perde importância no processo e deve entender que o sistema não será usado contra ele. Com a utilização do sistema, o vendedor pode atender seu cliente de forma personalizada e com qualidade, tendo acesso à história da relação entre empresa e cliente. Por sua vez, a empresa registra, em sistema de tecnologia, aquelas informações antes contidas apenas na memória de um ou de outro dos colaboradores de vendas.

Segundo Anderson (2002), em muitos contextos de marketing, o papel do vendedor é o de avaliar as necessidades do cliente, direcionar o cliente para um produto ou serviço apropriado e depois negociar com ele. Shoemaker (2001, p.178) diz que em muitas empresas "a força de vendas é à base das interações com os clientes". A integração tecnológica com cada ponto de toque existente entre empresa e cliente fortalece a habilidade da força de vendas de desenvolver relacionamentos adequados com os clientes. Para Speier e Venkatesh (2002) o pessoal de vendas constitui a fonte primária da troca de informações dentro do relacionamento entre cliente e vendedor e exerce papel crítico na formação e sustentabilidade dos relacionamentos com cliente.

Finalizando-se, há em Shoemaker (2001) que o pessoal de vendas em particular forma fortes conexões com os clientes. $\mathrm{O}$ autor entende a importância da preservação dos relacionamentos entre eles. Apresenta-se, no 'Quadro 1', a caracterização teórica da variável tecnológica do CRM, conhecida como SFA. Em seguida, a metodologia do estudo. 


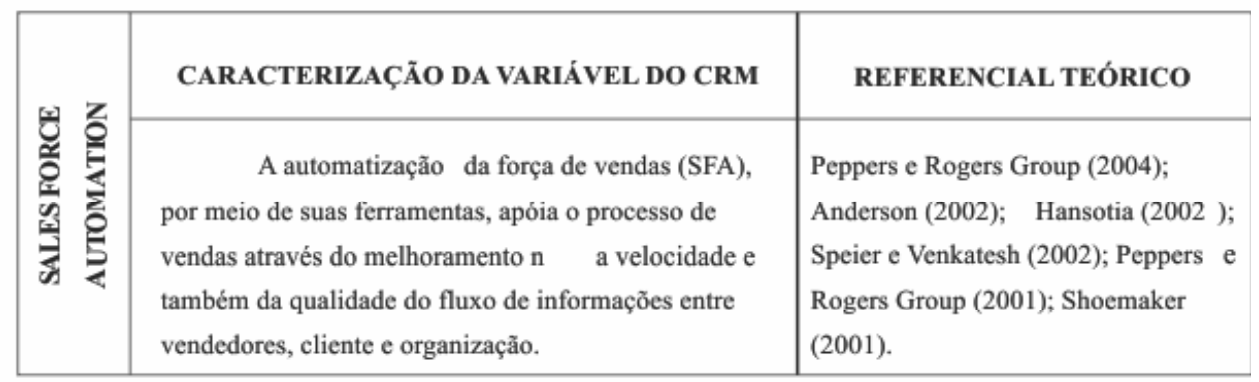

Quadro 1: Caracterização da SFA como indicador tecnológico do CRM. Fonte: do autor.

\section{METODOLOGIA DA PESQUISA}

Conforme referenciado por Yin (2001), um Estudo de Caso pode ter por finalidade a verificação de uma realidade específica. Diante dos propósitos de análise da realidade entre duas empresas, a opção foi seguir os preceitos qualitativos do autor. 0 presente estudo foi desenvolvido no formato de um Estudo de Caso, numa relação entre empresas. Trata-se de um estudo exploratório na busca do entendimento de uma solução de CRM desenvolvida na interação entre uma desenvolvedora e uma cliente e usuária da solução do software de CRM.

O termo exploratório, para Vieira $(2002$, p.65), se refere ao tipo de estudo que "visa a proporcionar ao pesquisador uma maior familiaridade com o problema". Malhotra (2001) diz que, quando os problemas a serem estudados são pouco conhecidos, a investigação qualitativa é a ideal. Zaltman (1997) complementa esses autores mencionando que o desenvolvimento de uma metodologia de pesquisa deve ser guiada pelo conhecimento sobre a natureza do fenômeno. Nesse caso, foi empregada metodologia qualitativa, exploratória e de intervenção direta, atendendo o entendimento da relação entre as empresas, no ponto em que interagem. Com base no estudo teórico sobre CRM e com base em específico na SFA, foram desenvolvidos roteiros de entrevistas semiestruturadas, aplicados para três executivos da empresa desenvolvedora e um da firma cliente e usuária da solução, por serem os detentores do tipo de conhecimento desejado na investigação. Antes da utilização dos roteiros, houve validação por Doutores da área de Marketing. Cada entrevista teve duração aproximada de uma hora e seus resultados estão descritos abaixo, no processo de análise. Uma entrevista extra, com especialista na área de tecnologia, foi aplicada com o objetivo de ampliar os insights mediante uma visão externa ao contexto, não sendo uma daquelas mencionadas anteriormente como fonte de elucidação. Para tanto, os preceitos apresentados pela especialista estão juntos aos elementos teóricos, diante do processo de estruturação dos resultados, o que pode ser melhor identificável na apreciação da 'Figura 1'.

Para Boyd e Westfall (1964, p.51), "a maioria das informações usadas em mercadologia são obtidas por meio de entrevistas", razão pela qual foi esse o procedimento para coleta dos dados. Diz Zaltman (1997, p.424) que "a linguagem verbal desempenha um importante papel na representação, armazenamento e comunicação do pensamento", reforçando a escolha da sistemática adotada na coleta dos dados. Quanto à análise dos resultados, foi feita uma Análise de Conteúdo seguindo Bardin (1977), por meio da triangulação entre entrevistas e teoria. Para o melhor entendimento da construção dos resultados, a figura já referida apresenta a síntese do processo de triangulação dos dados que proporcionaram a análise empírica da SFA em CRM. Na próxima parte deste artigo, estão os resultados gerais sobre SFA. 


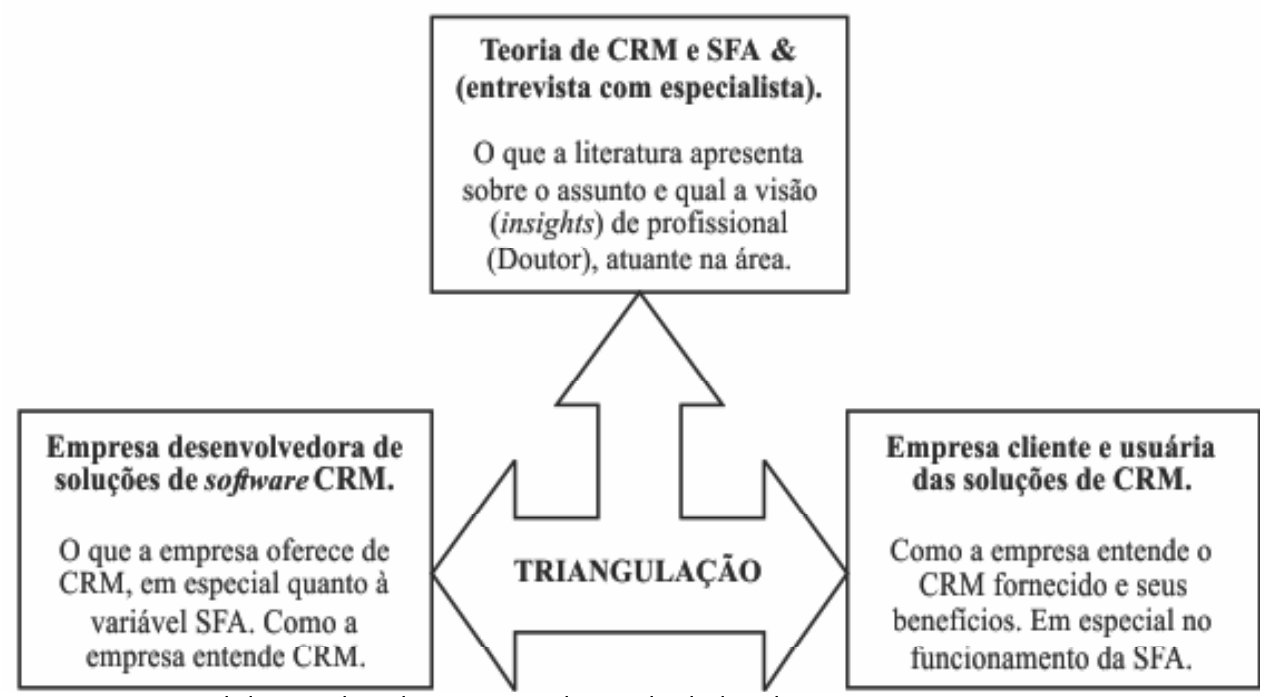

Figura 1: Metodologia adotada na triangulação de dados da pesquisa.

Registra-se que os nomes das empresas envolvidas serão preservados e, nesse sentido serão mencionadas no texto como empresa 'desenvolvedora' e empresa 'cliente-usuária'. Da mesma maneira, estão omitidos os nomes dos profissionais entrevistados, os quais serão citados de acordo com o cargo ocupado nas firmas, quando das entrevistas. A divisão analítica dos resultados a seguir está ao encontro do representado na 'Figura 1', basicamente expressa pela relação entre Teoria, Empresa 'desenvolvedora' e Empresa 'cliente-usuária' de CRM.

A empresa desenvolvedora de CRM do estudo é uma das maiores fabricantes de hardware do mundo, com destaque no segmento de impressoras. Atua também na confecção de software para projetos de grandes organizações. A empresa cliente é a maior emissora de televisão do Brasil, com abrangência em todo o território nacional, além de transmissões para outros países. Em relação ao tempo de mercado, são empresas maduras, com alto índice de inovação e participação. Na empresa desenvolvedora, predominam as formações na área de ciências da informação. Na firma cliente, as formações se concentram nas áreas de marketing, vendas e publicidade, em aderência ao negócio.

\section{RESULTADOS OBTIDOS DIANTE DA FERRAMENTA DE SALES FORCE AUTOMATION (SFA)}

Uma definição breve do propósito da automação da força de vendas é a de Speier e Venkatesh (2002), que a classifica como uma forma de vendas que utiliza tecnologias alinhadas com as estratégias de CRM. $O$ aspecto operacional do CRM está concentrado nessa plataforma tecnológica, na qual são realizadas interações com clientes e vendas (HANSOTIA, 2002). Na perspectiva citada por Speier e Venkatesh (2002), a SFA pode gerar excessivos conflitos internos com o pessoal de vendas. Entretanto, neste estudo, que envolve as empresas 'desenvolvedora' e 'cliente-usuária', ocorre o contrário do que relatam os autores quanto aos conflitos internos; estes não ocorrem na área de vendas da empresa 'cliente-usuária'.

Quando questionado, o Gerente de Projeto da 'desenvolvedora' sobre a força de vendas relatou que cada agência de publicidade, em cada cidade em que atua, possui um terminal de contato com a 'cliente-usuária', uma empresa nacional atuante na área de mídia. É o próprio sistema que faz 
a venda, mencionou o entrevistado: "a venda é automatizada", o que não deixa margem para dúvida quanto à aplicação de Sales Force Automation (SFA) no projeto investigado. $O$ início da transação comercial com a 'cliente-usuária' é feito pelas agências de publicidade, quando acessam um sistema para realizar a compra de espaço comercial. Conforme o primeiro entrevistado, os funcionários da 'cliente-usuária' veem essa aplicação como um benefício, já que operam o sistema recebendo comissão de venda. O aumento da qualidade, na visão desse executivo da 'desenvolvedora', é bem claro, já que se trata de um sistema controlado e que proporciona um atendimento mais rápido e eficiente. Conforme identificado a seguir, o segundo executivo da 'desenvolvedora' concorda.

O segundo colaborador entrevistado, o Gerente de Software da 'desenvolvedora', diagnosticou como sendo positiva a classificação da parte referente a vendas do sistema desenvolvido para a 'cliente-usuária' como uma ferramenta de automação das vendas (SFA). Ele descreveu o desempenho do processo, relatando que o sistema tem uma parte que é direcionada para o atendimento ao cliente, através da qual este realiza os negócios com a firma 'cliente-usuária'. É uma ferramenta interativa e direta no entendimento do gestor, e são evidentes as características SFA nesse módulo da aplicação de CRM. Porém, o Gerente não soube precisar como efetivamente funciona esse processo, já que os vendedores da 'cliente-usuária' também interagem com o sistema antes das negociações e também no decorrer desses processos. Com relação à visão dessa aplicação por parte do pessoal da cliente, a reação destes foi descrita como muito boa e permitiu à 'cliente-usuária' atuar em um campo de mercado significativamente maior e com mais segurança. A automação deslocou os funcionários para tarefas mais interessantes. A ferramenta é vista como um benefício através do qual se atingiu um aumento de qualidade.

Em relação a Sales Force Automation (SFA), o Líder de Projeto da 'desenvolvedora', o terceiro entrevistado na organização, afirmou que o sistema, através da aplicação web, é uma força de vendas nos moldes SFA. A 'desenvolvedora', no processo de desenvolvimento das soluções SFA, contou com o apoio de seus vendedores para realizar a negociação com a empresa 'cliente-usuária' de CRM/SFA. O processo de definição dos atributos da solução desta parte do cliente (empresa 'cliente-usuária'), como é normal nos negócios desenvolvidos pela empresa 'desenvolvedora', foi uma ideia concebida pela equipe de desenvolvimento de software, que verificou as oportunidades de implantação. Embora as ideias partam do setor de desenvolvimento do qual o entrevistado é o líder direto, o processo de vendas é feito pela equipe de vendas da 'desenvolvedora'. Ainda que os desenvolvedores montem as soluções, somente quem pode acatar definições e termos da negociação é a equipe de vendas da 'desenvolvedora'. Para finalizar com o entrevistado, em relação à SFA, foi questionado sobre o aspecto mais relevante para o estudo. Pediu-se que o Líder de Projeto da 'desenvolvedora' emitisse o seu parecer a respeito de como ele percebeu a reação da força de vendas da empresa cliente no momento em que o sistema assumiu as funções antes exercidas por vendedores. Como complemento, o colaborador da 'desenvolvedora' foi questionado sobre a maneira que a força de vendas da 'clienteusuária' reagiu perante SFA, se expressando uma visão de ameaça ou de melhoria para o exercício de seus afazeres. Relatou o entrevistado que, anterior ao sistema desenvolvido, já existia outro sistema operante em outra estrutura de envio de arquivos dos clientes da 'cliente-usuária', menos eficiente que o desenvolvido, classificado pelo entrevistado como "arcaico". A integração dos sistemas com o novo sistema de CRM, o qual substituiu o método antigo, gerou um aumento de qualidade, pois passou a existir uma janela mais ampla de diálogo da empresa 'cliente-usuária' com os seus clientes finais. Novamente, o entrevistado foi enfático ao dizer: "creio que eles veem o sistema como uma arma, uma ferramenta que melhorou o trabalho deles". Essa percepção é um aspecto crucial neste estudo e engloba mais do que apenas tecnologia, relacionando-a com os aspectos organizacionais que fazem parte das soluções de CRM. Nota-se uma diferença desse caso em relação aos preceitos gerais encontrados na teoria, o que amplia as possibilidades de reflexão. 
Para endossar que o sistema desenvolvido se trata de uma solução de CRM, o depoimento fornecido pelo gestor principal do programa de vendas na empresa 'cliente-usuária', além de complementar as citações dos colaboradores da empresa 'desenvolvedora', demonstrou o aspecto relacional do sistema. O Gerente de Projeto mencionou que a venda automatizada utilizada não é um sistema que opera como simples portal de venda sem contato com clientes. Embora a solução de compra do sistema seja eletrônica, ainda existem contatos de negociação prévia via sistema através dos quais existe interação entre vendedor e clientes.

Esse canal é utilizado para as ações diretas com os clientes e mantém uma conexão constante de relacionamento. Trata-se de um canal de relacionamento aberto que pode ser utilizado para ações de CRM. Questionado sobre as impressões deixadas pelo sistema aos colaboradores da empresa 'cliente-usuária' e aos seus clientes finais, o entrevistado mencionou que a comunicação entre a 'cliente-usuária' e as agências (clientes finais) melhorou e que a utilização das informações de negócio também seguiu o mesmo caminho. Essa melhoria nas negociações foi atribuída ao formato de operação do sistema, no qual as duas pontas que interagem visualizam mesmos dados. As mudanças culminaram no aumento da qualidade. Por fim, há a apresentação da síntese da entrevista com especialista em tecnologias de negócios, a qual está alinhada com a teoria no processo posterior de análise dos resultados.

$\mathrm{Na}$ opinião do profissional de $\mathrm{Tl}$, que é professor Doutor atuante em instituição do Canadá, na área de negócios, com relação ao conceito do que é a automatização da força de vendas, diz que SFA se trata de um sistema de ordem operacional, que permite o agrupamento e armazenagem de dados relevantes sobre as vendas. São dados utilizados pelo pessoal de vendas como uma ferramenta de suporte, em que estão contidas informações sobre transações passadas, histórico de contatos, produtos comprados e outros. Esse tipo de sistema permite que, mesmo com a existência de distância geográfica, exista a possibilidade de acesso a todos os dados necessários, sejam dos clientes ou da própria empresa. Quanto à percepção das pessoas que antes faziam os trabalhos os quais se tornaram automatizados, a opinião do professor é de que estas, em geral, irão gostar.

O critério defendido para a aprovação da SFA pelas pessoas é que, através da utilização dessa sistemática de trabalho, os colaboradores poderão desempenhar as suas tarefas utilizando-se de informações em formato online atualizadas e com maior qualidade, diz o professor entrevistado. Esse sistema é um suporte tecnológico que permite aos agentes de venda abandonar os métodos antigos de armazenagem de informações. $O$ foco dos vendedores, mediante a adoção da SFA, fica voltado para fatores mais importantes do processo de negociação com os clientes da organização.

Descritos de maneira geral, os resultados das entrevistas e da teoria, e o processo de triangulação dos dados, seguem expressos no 'Quadro 2', de modo mais completo e no formato resumido no 'Quadro 3', localizado nas considerações finais deste estudo. 0 mais importante até este ponto identificado, é que as entrevistas (representando profissionais de ambas as empresas e profissional especialista da área) não estão relacionadas diretamente com os preceitos teóricos. De encontro aos resultados esperados, teoria e prática, neste caso específico (dadas limitações metodológicas), podem indicar uma lacuna para estudos.

A questão emergente que se formou foi: 'por que os resultados desse caso não condizem com a teoria sobre SFA?'. Como uma possível resposta, identificou-se que as forças de vendas envolvidas nessa relação entre empresas são detentoras de conhecimentos aprimorados de tecnologia, sendo as empresas líderes em seus respectivos mercados. Evidências indicam que se trata de uma relação entre empresas maduras quanto à aplicação da SFA, diferentes da maioria dos casos investigados sobre automação de vendas. 
Nas considerações finais, essa possibilidade é mais bem explorada, e o 'Quadro 3' ilustra de maneira direta e objetiva a situação singular encontrada nesta pesquisa. Sugere-se uma investigação mais apurada para identificar com precisão esse tipo de fenômeno em SFA, o que pode ser desenvolvido por outros Estudos de Caso com mesmas bases de análise, ou através da utilização de métodos de pesquisa mais sofisticados. Quiçá investigações mais abrangentes, com maior poder de generalização para os resultados, relevando na análise maior quantidade de empresas que utilizam a SFA como parte das ações e programas de CRM.

\begin{tabular}{|c|c|c|c|c|c|}
\hline 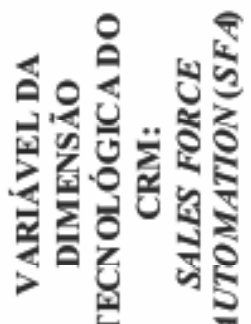 & $\begin{array}{c}\text { EMPRESA } \\
\text { DESENVOLVEDORA } \\
\text { DA SOLUÇÃO DE } \\
\text { CRM }\end{array}$ & $\begin{array}{c}\text { EMPRESA } \\
\text { CLIENTE } \\
\text { USUÁRIA } \\
\text { DA } \\
\text { SOLUÇÃO } \\
\text { DE CRM }\end{array}$ & $\begin{array}{c}\text { TEORIA } \\
\text { REFERENTE } \\
\text { À VARIÁVEL } \\
\text { DO CRM } \\
\text { INTITULADA } \\
\text { SFA }\end{array}$ & $\begin{array}{l}\text { CONGRUÊNCIAS } \\
\text { OBTIDAS NO } \\
\text { ESTUDO }\end{array}$ & 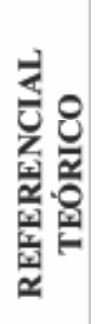 \\
\hline & 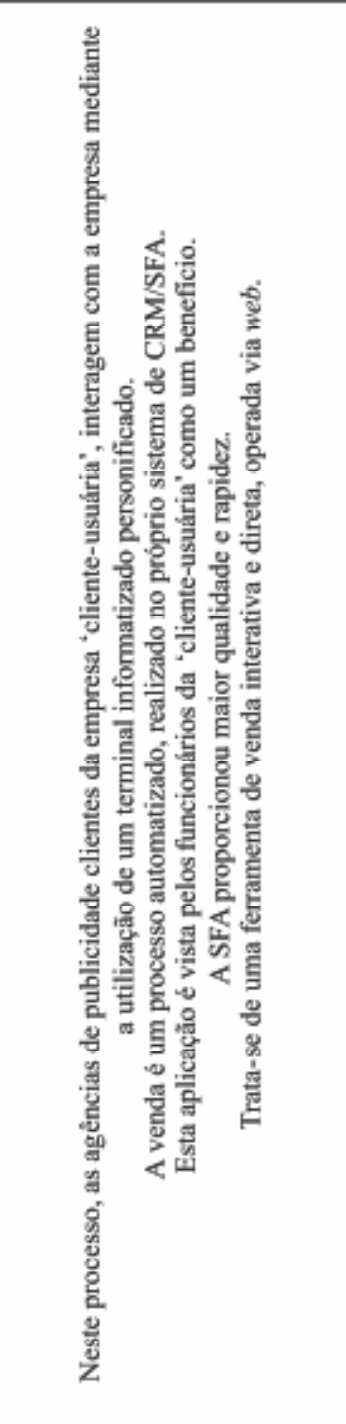 & 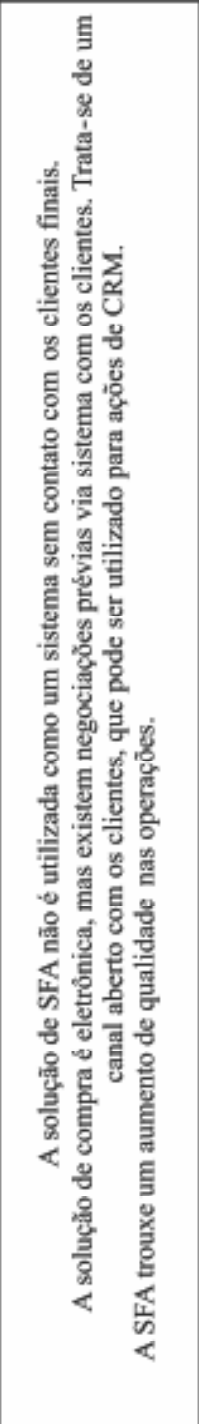 & 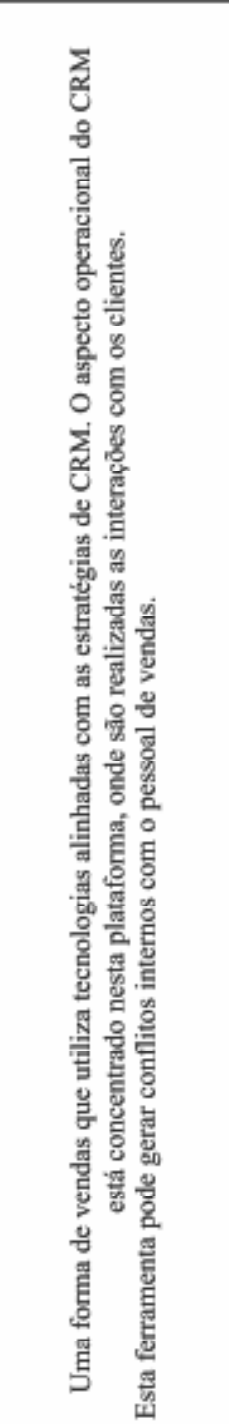 & 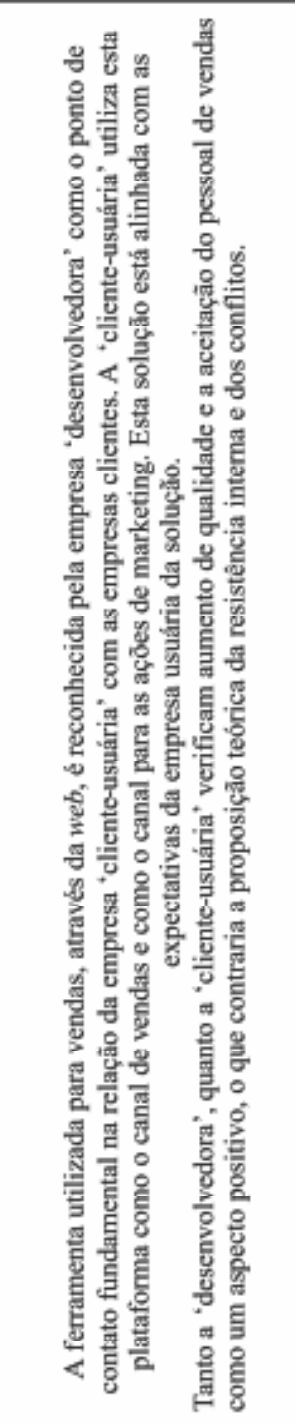 & 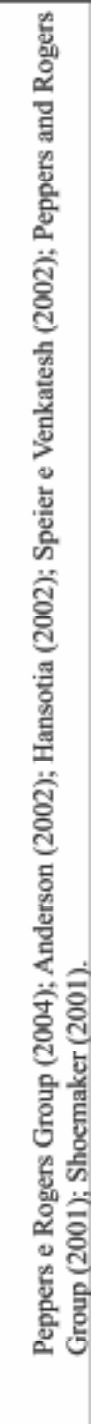 \\
\hline
\end{tabular}

Quadro 2: Apresentação dos resultados gerais do Estudo de Caso. Fonte: do autor. 


\section{CONSIDERAÇÕES FINAIS}

$\mathrm{Na}$ relação entre as empresas e na compreensão mútua da aplicabilidade e de desenvolvimento, a variável SFA mostrou-se congruente. $O$ aspecto que impede considerar a totalidade da ferramenta decorre da percepção diversa da prática com a teoria. Do ponto de vista tecnológico, existe a tríade congruência. Já quanto aos efeitos esperados, a teoria enfatiza a possibilidade da geração de conflitos na organização adotante, perante a equipe de vendas, o que, na prática, não ocorreu. Ambas as empresas e seus respectivos colaboradores abordaram a SFA como uma ferramenta de melhoria nas condições de trabalho, amplamente aceita. Para melhor ilustração desse resultado, no 'Quadro 3', está apresentada a síntese das congruências.

\begin{tabular}{|c|c|}
\hline $\begin{array}{c}\text { VARIÁVEL DA DIMENSÃO } \\
\text { TECNOLÓGICA DO CRM }\end{array}$ & $\begin{array}{c}\text { CONGRUÊNCIAS OBTIDAS NO ESTUDO SOBRE CRM } \\
\text { FOCADO NA FERRAMENTA DE SFA }\end{array}$ \\
\hline SALES FORCE AUTOMATION (SFA) & $\begin{array}{l}\text { O indicador é congruente na relação entre as empr esas, } \\
\text { mas é contrário ao que está referenciado pela teoria. As resistências } \\
\text { internas e os conflitos relatados pela teoria não ocorreram no caso } \\
\text { entre empresas, onde os envolvidos vêem na SFA uma melhoria. }\end{array}$ \\
\hline
\end{tabular}

Quadro 3: Síntese dos resultados obtidos através da análise de congruências no estudo. Fonte: do autor.

Apesar dos importantes resultados indicando congruências práticas, mas não teóricas, quanto aos efeitos ao longo do tempo, é preciso que mais estudos sejam feitos em busca da compreensão dos motivadores dessa perspectiva. É necessário buscar outros casos para verificar o comportamento prático diante da teoria, e, se o estudo entre as empresas pesquisadas for diferenciado dentre a maioria dos casos, é pertinente uma nova investigação para identificar o porquê de esta relação resultar em diferencial diante de outras.

Uma das possibilidades a ser investigada pode residir na dificuldade de desempenhar os processos sem o uso da SFA, indicando uma das razões para que o pessoal de vendas veja a automatização como uma ferramenta de apoio. No caso da empresa 'cliente-usuária', o seu tipo de vendas é complexo e atende uma natureza específica de transações (venda de espaço comercial, o que enfrenta a necessidade de adequação entre as programações nacional, estadual e regional). De fato, os vendedores da empresa 'cliente-usuária', mediante o uso desta aplicação tecnológica (SFA), tratam tal inovação como uma ferramenta que reduz os equívocos e que permite o foco restrito na venda, e não na possibilidade de vender um espaço comercial já ocupado para outro cliente, gerando inconvenientes e insatisfação.

Por se tratar de um Estudo de Caso, como já referido, as limitações incluem a generalização dos resultados. Porém, essas divergências entre a prática específica e a composição teórica reforçam que não existe uma fórmula específica para o sucesso em aplicações de SFA com base em CRM. Ao contrário, CRM se trata de uma complexa relação entre filosofia empresarial, emprego tecnológico e outras contingências, que irão variar por uma série de fatores, como por exemplo, porte empresarial, setor de atividade, tipo de clientes e, até mesmo, outros critérios referentes ao estudo do Comportamento do Consumidor. O sucesso ou o fracasso, em CRM e SFA, não respondem por uma cartilha com tópicos prédelineados. Compete aos gestores de projeto o adequado mapeamento da situação de sua organização. 
Em termos de avanço acerca do estudo sobre o CRM no Brasil, este artigo atende até certo ponto ao que mencionam Pinto e Lara $(2010$, p.13) da necessidade de desenvolver pesquisas "mais abertas à voz do consumidor na sua vida cotidiana". Embora não seja abrangente ao ponto de consultar ao cliente final, a aplicação metodológica do estudo de caso mediante técnicas como a de entrevistas possibilita a obtenção de pareceres mais próximos da vida de trabalho diária dos agentes. Se, por um lado, não permite as generalizações dos estudos quantitativos, por outro, é o caminho alternativo para investigar a significação e os entendimentos dos envolvidos nas práticas e nesse caso, também no desenvolvimento da operação de CRM.

Uma alternativa para identificação de elementos relevantes a serem estudados no contexto do CRM são os artigos de levantamento ou de mapeamento do campo. Atendendo esses critérios, Demo-Fiuza et al. (2011) e Brambilla (2010) servem como pontos de partida na identificação de lacunas e possibilidades para estudos futuros. O primeiro apresenta uma caracterização do campo no Brasil, com as formações e atuações dos grupos de pesquisa sobre a temática. Já o segundo trabalho faz uma abordagem relacionada aos temas investigados no contexto nacional e demonstra que os estudos qualitativos predominam no país. Embora grande parte dos estudos em CRM seja de caráter qualitativo, poucos são interpretacionistas e aplicados diretamente aos consumidores (grande parte dos estudos centraliza a análise nas firmas). Nesse sentido, as propostas de Pinto e Lara (2010) por pesquisas interpretativas constituem uma alternativa importante para avançar no estudo sobre CRM em geral e acerca do comportamento do consumidor em específico. 


\section{REFERÊNCIAS BIBLIOGRÁFICAS}

ANDERSON, E. T. Sharing the Wealth: When Should Firms Treat Customers as Partners? In: Management Science v.48, n.8, p.955-971, 2002.

ATUAHENE-GIMA, K.; MURRAY, J.Y. Antecedents and Outcomes of Marketing Strategy Comprehensiveness. In: Journal of Marketing, v.68, p.33-46, 2004.

BARDIN, L. Análise de Conteúdo. Lisboa: Edições 70, 1977.

BERRY, L. L. Relationship Marketing of Services: Perspectives from 1983 and 2000. In: Journal of Relationship Marketing, v.1, n.1, p.59-77, 2002.

BOYD, H. W.; WESTFALL, R. Pesquisa Mercadológica: Textos e Casos. v. I. Rio de Janeiro: USAID, 1964.

BRAMBILLA, F. R.. Análise Qualitativa da Produção Acadêmica Brasileira sobre Customer Relationship Management (CRM): O Primeiro Passo em Busca da Consolidação Conceitual. Revista Ciências Exatas e Naturais, RECEN, v.12, n.2, p.1-27, 2010.

CROTEAU, A. ; LI, P. Critical Success Factors of CRM Technological Initiatives. Canadian Journal of Administrative Sciences, v.20, n.1, p.21-34, 2003.

DEMO-FIUZA, G.; OLIVEIRA, K. R. t; PONTE, V.; FERREIRA, L. A.; MENDES, N. M. D. Marketing de Relacionamento (CRM): Estado da Arte, Produção Nacional na Primeira Década do Milênio e Agenda de Pesquisa. In: XXXV Encontro da ANPAD, (p.1-17), Rio de Janeiro, RJ, 4 a 7 de setembro de 2011 .

DWYER, F. R. ; SCHURR, P. H.; OH, S. Developing Buyer-Seller Relationships. In: Journal of Marketing, v.51, p.11-27, 1987.
ERNST, H. ; HOYER, Wayne D.; KRAFFT, Manfred; KRIEGER, Katrin. Customer Relationship Management and Company Performance: The Mediating Role of New Product Performance. In: Journal of the Academy of Marketing Science, v.39, p.290-306, 2011.

HANSOTIA, B. Gearing up for CRM: Antecedents to Successful Implementation. In: Journal of Database Marketing, v.10, n.2, p.121-132, 2002.

IM, S.; WORKMAN Jr., John P. Market Orientation, Creativity, and New Product Performance in High-Technology Firms. In: Journal of Marketing, v.68, p.114-132, 2004.

KAVANAGH, S. Planning for CRM Success. In: Government Finance Review, v.19, n.4, p.3945, 2003.

LIN, Y.; SU, Hwan-Yann. Strategic Analysis of Customer Relationship Management: A Field Study on Hotel Enterprises. In: TQM \& Business Excellence, v.14, n.6, p.715-731, 2003.

MAlHOtRA, N. K. Pesquisa de Marketing: Uma Orientação Aplicada. 3.ed. Porto Alegre: Bookman, 2001.

NANCARROW, C. ; REES, S. ; STONE, M. New Directions in Customer Research and the Issue of Ownership: A Marketing research Viewpoint. In: Database Marketing \& Customer Strategy Management, v.11, n.1, p.26-39, 2003.

OLSEN, S. O. Comparative Evaluation and the Relationship between Quality, Satisfaction, and Repurchase Loyalty. In: Journal of the Academy of Marketing Science, v.30, n.3, p.240-249, 2002.

O'MALLEY, L. ; MITUSSIS, D. Relationships and Technology: Strategic Implications. In: Journal of Strategic Marketing, v.10, p.225-238, 2002. 
PARASURAMAN, A.; COLBY, C. L. Marketing para Produtos Inovadores: como e por que seus clientes adotam tecnologia. Porto Alegre: Bookman, 2002.

PEPPERS \& ROGERS GROUP. CRM Series: Marketing 1 to 1. 3.ed. São Paulo: Peppers \& Rogers Group Brasil e Makron Books, 2004.

PEPPERS AND ROGERS GROUP. CRM Series: Call Center 1 to 1. São Paulo: Makron Books, 2001.

PINTO, M. ; LARA, J. E. O Marketing de Relacionamento no Mercado Consumidor em uma Perspectiva Experiencial e Simbólica: Buscando Novas Proposições para Pesquisas. In: IV Encontro de Marketing da ANPAD, EMA, (p.117). Florianópolis, SC, 23 a 25 de maio de 2010.

RAGINS, E. J.; GRECO, Alan J. Customer Relationship Management and E-Business: More than a Software Solution. In: Review of Business, p.25-30, 2003.

ROGERS, B. What Gets Measured Gets Better. In: Journal of Targeting, Measurement and Analysis for Marketing, v.12, n.1, p.20-26, 2003.

ROWE, W. G. ; BARNES, J. G. Relationship Marketing and Sustained Competitive Advantage. In: Journal of Market Focused Management, v.2, p.281-297, 1998.

SCHIFFMAN, L.G.; KANUK, L. L. Consumer Behavior. 6.ed. New Jersey: Prentice Hall, 1997.

SHETH, J. N.; ESHGHI, A. ; KRISHNAN, B. C. Marketing na Internet. Porto Alegre: Bookman, 2002.

SHOEMAKER, M. E. A Framework for Examining IT-Enabled Market Relationships. In: Journal of Personal Selling \& Sales Management, v.21, n.2, p.177-185, 2001.
SPEIER, C.; VENKATESH, V. The Hidden Minefields in the Adoption of Sales Force Automation Technologies. In: Journal of Marketing, v.66, p.98-111, 2002.

VIEIRA, V. A. As tipologias, variações e características da pesquisa de marketing. In: Revista da FAE, v.5, n.1, p.61-70, 2002.

WEBer, Max. A Ética Protestante e o Espírito do Capitalismo. São Paulo: Martin Claret, 2003.

WILSON, H. ; DANIEL, E.; McDONALD, M. Factors for Success in Customer Relationship Management (CRM) Systems. In: Journal of Marketing Management, v.18, p.193-219, 2002.

WINER, R. S. A Framework for Customer Relationship Management. In: California Management Review, v.43, n.4, p.89-105, 2001.

YIN, R. K. Estudo de Caso: Planejamento e Métodos. 2.ed. Porto Alegre: Bookman, 2001.

ZALTMAN, G. Rethinking Research: Putting People Back In: Journal of Marketing Research, v.34, p.424-437, 1997. 